\title{
Solid lipid nanoparticles of irbesartan: preparation, characterization, optimization and pharmacokinetic studies
}

\author{
Deepthi Soma, Zenab Attari, Meka Sreenivasa Reddy, Atmakuri Damodaram, Kunnatur \\ Balasundara Gupta Koteshwara*
}

\author{
Department of Pharmaceutics, Manipal College of Pharmaceutical Sciences, Manipal University, Manipal, India
}

\begin{abstract}
Irbesartan is an antihypertensive with limited bioavailability and solid lipid nanoparticles (SLN) is one of the approaches to improve bioavailability. Solid lipid nanoparticles were prepared using glyceryl monostearate by solvent emulsification method followed by probe sonication. Irbesartan loaded SLNs were characterized and optimized by parameters like particle size, zeta potential, surface morphology entrapment efficiency and in vitro release. The optimized formulation was then further evaluated for the pharmacokinetic studies in Wistar rats. Irbesartan-loaded SLN of particle size $523.7 \mathrm{~nm}$ and $73.8 \%$ entrapment efficiency showed good bioavailability in Wistar rats and also showed optimum stability in the studies. The SLN prepared using glyceryl monostearate by solvent emulsification method leads to improve bioavailability of the drug.
\end{abstract}

Uniterms: Irbesartan/pharmacokinetics. Irbesartan/preparation. Irbesartan/bioavailability. Glyceryl monostearate. Solid lipid nanoparticles/characterization.

\section{INTRODUCTION}

Colloidal systems are the most promising alternative drug delivery systems for improving the bioavailability and therapeutic availability of the drugs. The colloidal systems include micelles, vesicles, liposomes, liquid crystals, nanocrystals, nanoparticles, etc. The particle size of the mentioned nano-carriers varies from 10 to 800 $\mathrm{nm}$. Solid lipid nanoparticles (SLN) comprises solid lipid core stabilized by a surfactant at interfacial region. The solid lipids are used for the preparation of SLN instead of liquid lipids (used in case of liposomes) to overcome the disadvantages associated with the liquid state and to improve physical stability. SLN possesses advantages over other colloidal delivery systems of increased physical stability, high drug payload and absence of carrier biotoxicity. The preparation of SLN can also be extrapolated to large scale production. The methods viz., high pressure homogenization, solvent evaporation, solvent emulsification, ultrasonication etc. are reported to be used for the preparation of solid lipid nanoparticles (Mehnert,

\footnotetext{
*Correspondence: K.B. Koteshwara. Department of Pharmaceutics. Manipal College of Pharmaceutical Sciences. Manipal University, Manipal, India. Phone: 0820-2574187 / Fax: 91-0820-2571998. E-mail: kb.koteshwara@manipal.edu
}

Mader, 2001; Muller, Mader, Gohla, 2000; Uner, 2006).

Irbesartan is an angiotensin II receptor antagonist, used for the management of hypertension. The drug is practically insoluble in water. It has $90 \%$ plasma protein binding and $60-70 \%$ bioavailability. Therefore, large therapeutic doses ( $75 \mathrm{mg}$ to $300 \mathrm{mg}$ ) are required for the required effect. Several approaches as solid dispersion or polymeric nanoparticles or inclusion complex with cyclodextrin have been reported to improve the bioavailability of the drug. However, various literature suggested solid lipid nanoparticle as an efficient way to improve bioavailability of drugs along with improved physical stability (Ganapuram et al., 2013; Zhang et al., 2012; Hirlekar, Kadam, 2009). Thus, the present study was carried out with the aim to improve the solubility and dissolution profile of irbesartan by preparing its solid lipid nanoparticles using the solvent emulsification method. The prepared nanoformulation was characterized and evaluated for in vitro release and in vivo studies.

\section{MATERIALS AND METHOD}

Irbesartan was received as a gift sample from Lupin Research Park Ltd, Pune, India. All the chemicals used in the study were of analytical grade. 


\section{Method of preparation of solid lipid nanoparticle}

The solid lipid nanoparticles (SLNs) were prepared by a solvent emulsification method. Glyceryl monostearate (GMS) was dissolved in organic phase (ethanol) by heating at $70-80^{\circ} \mathrm{C}$ and $75 \mathrm{mg}$ of irbesartan was dissolved by adding in to the solution. The prepared solution was added to a hot poloxamer 407 (P407) solutions $\left(5^{\circ} \mathrm{C}\right.$ above melting point of the lipid) under stirring using a polytron homogenizer at $15,000 \mathrm{rpm}$ for 15 minutes. The resultant dispersion was immediately sonicated using a probe sonicator at amplitude of $50 \%$ with the pulse of $4 \mathrm{sec}$ intervals. After probe sonication the organic solvents present in the solution was evaporated using rotavapour for 2 hours at $80 \mathrm{rpm}$. The prepared SLN samples were freeze dried at $-48^{\circ} \mathrm{C}$ for 24 hours to yield dry powder. The amount of irbesartan was fixed, i.e., $75 \mathrm{mg}$. whereas, the amount of GMS and P407 was varied. Various batches coded as F1 to F5 and P1 to P5 with varying the amount of GMS and P407, respectively were prepared (Table I).

\section{Determination of particle size, polydispersity index (PDI) and zeta potential}

The particle size (PS), polydispersity index and zeta potential of the prepared SLN before and after freeze drying was measured using Malvern Nano ZS zetasizer. All the measurements were performed in triplicate. The various batches were evaluated to optimize the SLN for further studies.

\section{Drug entrapment efficiency}

Entrapment efficiency of the drug in SLNs was determined by quantifying the amount of free drug in the dispersion medium using below equation

$$
\mathrm{EE}(\%)=\frac{\text { Mass of drug in submicron particles }}{\text { Mass of drug used in formulation }} \times 100
$$

$10 \mathrm{mg}$ of freeze dried irbesartan-loaded SLN was dissolved in $5 \mathrm{~mL}$ of ethanol. $1 \mathrm{ml}$ of the above solution was diluted to $10 \mathrm{ml}$ with phosphate buffer $\mathrm{pH} 7.4$ and filtered using $0.45 \mu \mathrm{m}$ membrane filters. The absorbance of the filtered solution was recorded by UV spectrophotometer at $244 \mathrm{~nm}$ (UV-1601PC, Shimadzu, Japan).

\section{In vitro release studies}

The in vitro dissolution or release study of the optimized freeze dried irbesartan-loaded SLN (F3) was carried using USP Type I dissolution apparatus (Basket method) at $50 \mathrm{rpm}$. The equivalent amount of formulation F3 was taken containing $75 \mathrm{mg}$ of irbesartan. The test was carried out in $900 \mathrm{~mL}$ of $0.1 \mathrm{~N} \mathrm{HCl}$ for the first 2 hours, followed by the $\mathrm{pH} 7.4$ phosphate buffer containing $0.25 \%$ tween 80 solution. The temperature of the dissolution medium was maintained at $37 \pm 0.5^{\circ} \mathrm{C}$, keeping it in thermostatically controlled water. The samples were withdrawn at predetermined time intervals, i.e. $0.5,1,2$, $2.5,3,4,5,6,8,12,24$ and 48 hours and replaced with fresh dissolution media. The drug concentration was determined

TABLE I - Composition and characterization of the prepared SLNs

\begin{tabular}{lccccccc}
\hline Formulation & GMS (\%) & P407 (\%) & \multicolumn{2}{c}{ Before freeze drying } & \multicolumn{2}{c}{ After freeze drying } & $\begin{array}{c}\text { Zeta } \\
\text { potential } \\
\text { (mv) }\end{array}$ \\
\hline F1 & & $\begin{array}{c}\text { Particle Size } \\
(\mathbf{n m}) \pm \text { SD }\end{array}$ & PDI & $\begin{array}{c}\text { Particle Size } \\
(\mathbf{n m}) \pm \text { SD }\end{array}$ & PDI & -19.3 \\
F2 & 2 & 1.5 & $363 \pm 9.19$ & 0.263 & $437.2 \pm 9.05$ & 0.386 & -16.5 \\
F3 & 2.5 & 1.5 & $380 \pm 1.41$ & 0.418 & $536.8 \pm 2.26$ & 0.662 & -21.5 \\
F4 & 3 & 1.5 & $523.7 \pm 15.6$ & 0.266 & $629.2 \pm 14.7$ & 0.526 & -20.0 \\
F5 & 3.5 & 1.5 & $550 \pm 14.14$ & 0.354 & $678 \pm 7.77$ & 0.725 & -16 \\
P1 & 4 & 1.5 & $617.2 \pm 1.97$ & 0.241 & $534 \pm 11.31$ & 0.625 & -17.6 \\
P2 & 3 & 2 & $672 \pm 2.12$ & 0.450 & $712 \pm 16.26$ & 0.506 & -14.3 \\
P3 & 3 & 2.5 & $709.2 \pm 1.97$ & 0.243 & $809 \pm 2.12$ & 0.276 & -13.9 \\
P4 & 3 & 3 & $836 \pm 9.19$ & 0.1913 & $842.3 \pm 4.45$ & 0.243 & -19.3 \\
P5 & 3 & 3.5 & $826 \pm 3.53$ & 0.812 & $936.1 \pm 5.02$ & 0.386 & -13.3 \\
\hline
\end{tabular}

The particle size is expressed as Mean $\pm \mathrm{SD}$. 
by measuring absorbance spectrophotometrically at 244 nm.

\section{Shape and surface morphology}

The morphology of the optimized freeze dried irbesartan-loaded SLN F3 was studied by scanning electron microscopy (SEM).

\section{Differential scanning calorimetry (DSC) and FT-IR spectroscopy}

DSC analysis and FT-IR spectroscopy of the pure drug and the optimized freeze dried irbesartan-loaded SLN F3 was performed. For DSC, the samples were placed in a sealed aluminium pan and heated under $\mathrm{N}_{2}$ flow $(30 \mathrm{~mL} / \mathrm{min})$ at a scanning rate of $5{ }^{\circ} \mathrm{C} / \mathrm{min}$ from 25 ${ }^{\circ} \mathrm{C}$ to $250{ }^{\circ} \mathrm{C}$. Empty aluminium pan was considered a reference. Duplicate determinations were carried out for each sample. Infrared spectroscopy was performed using a Shimadzu FT-IR 8300 spectrophotometer and the spectra were recorded in duplicate for each of the samples at the region of 4000 to $400 \mathrm{~cm}^{-1}$.

\section{Pharmacokinetic Studies}

Animals

Male Wistar rats weighing 200-250 g were used in the study. The pharmacokinetic study protocol was approved by the Institutional Animal Ethical Committee, Manipal University, Manipal (vide\# IAEC/KMC/18/20102011). Three animals were housed in each cage. Animals had free access to food and water.

\section{Bio-analytical method}

The concentration of irbesartan in the plasma samples was estimated by reversed-phase HPLC (HPLC, LC-2010 CHT, Shimadzu Corporation, Kyoto, Japan) (Erk, 2003). The chromatography was performed using column, Licrospher RP C $18(250 \times 4.6 \mathrm{~mm}, 5 \mu)$. The mobile phase used was $10 \mathrm{mM}$ phosphate buffer, $\mathrm{pH}$ 3.0 :acetonitrile $(55: 45 \% \mathrm{v} / \mathrm{v})$. The flow rate was $1 \mathrm{~mL} /$ $\mathrm{min}$. The mobile phase was filtered through $0.45 \mu \mathrm{m}$ nylon filters (Millipore, USA). Samples were injected at $50 \mu \mathrm{L}$ volume and the peaks were recorded at a wavelength 244 $\mathrm{nm}$. The concentrations were computed and compared.

\section{Oral administration}

Animals were randomized into two groups comprising three animals in each group. Animal were fasted overnight with free access to water. The pure irbesartan and the optimized irbesartan-loaded SLN F3 were administered orally at doses of $10 \mathrm{mg} / \mathrm{kg}$. Four to six hundred microlitres of blood was collected using heparinized capillaries from retro orbital plexus. The time intervals of $0.25,0.75,1,2,4,8,12$ and 24 hours were prefixed (Davi et al., 2000). The blood samples were centrifuged at 10,000 rpm for 5 minutes (Spinwin, Tarson, Kolkata). The plasma was separated and stored at $-80{ }^{\circ} \mathrm{C}$ until further analysis. The samples were analysed using HPLC.

\section{Extraction of irbesartan from rat plasma}

Briefly $95 \mu \mathrm{L}$ of blank rat plasma was taken in the $1.5 \mathrm{~mL}$ centrifuge tube and $5 \mu \mathrm{L}$ of irbesartan of varying concentrations and $10 \mu \mathrm{L}$ of internal standard (IS) working stock solution $(50 \mu \mathrm{g} / \mathrm{mL}$ of telmisartan $)$ was added and vortexed for 1 minute. Then $250 \mu \mathrm{L}$ of extracting solvent of methanol was added, vortexed for 10 minutes and centrifuged at 10,000 rpm for 5 minutes. The clear supernatant was transferred to HPLC vial and $50 \mu \mathrm{L}$ was injected in the HPLC system for analysis.

\section{Pharmacokinetic analysis}

The pharmacokinetic parameters such as $\mathrm{t}_{1 / 2} \beta$, $\mathrm{C}_{0}$, clearance $(\mathrm{Cl})$ and volume of distribution $\left(\mathrm{V}_{\mathrm{d}}\right)$ were determined using non-compartmental analysis, PK solution 2.1 software (Summit research Services, Montrose, Colorado, USA). Area under the curve (AUC) from zero to infinity was computed using the trapezoidal method. The terminal elimination rate constant $(\beta)$ was determined from log linear concentration versus time plot and eventually, the half life $\left(t_{1 / 2} \beta\right)$ was calculated using formula $0.693 / \beta$. The plasma drug concentration of irbesartan at time zero $\left(\mathrm{C}_{0}\right)$ was obtained by extrapolating time-plasma concentration profiles (Arumugam et al., 2009).

\section{Statistical analysis}

Statistical analysis was carried out using software, SPSS 11.5 package (University of Cambridge, UK). The difference in the parameters was analysed by unpaired student's T-test at $95 \%$ confidence interval. The difference was considered statistically significant at $\mathrm{p}<0.05$.

\section{Stability studies}

The optimized freeze dried irbesartan-loaded SLN (F3) was evaluated for the accelerated stability studies in accordance with the ICH guidelines. India falls into zone 3 as per the ICH guidelines and the accelerated studies are to be carried out at $40{ }^{\circ} \mathrm{C} \pm 2{ }^{\circ} \mathrm{C}$ temperatures and $75 \pm 5 \%$ 
relative humidity for a period of 45 days. The samples were withdrawn at predetermined time periods, i.e. 15,30 and 45 days and evaluated for drug content and mean particle size.

\section{RESULTS}

\section{Particle size, polydispersity index and zeta potential}

The particle size and PDI of the prepared batches were measured before and after freeze drying. The particle size was observed in the range of 360 to $1129 \mathrm{~nm}$ with zeta potential -13 to $-21.5 \mathrm{mV}$ for the prepared batches of SLN. It has been observed that an increase in lipid content (GMS) does not significantly affect the particle size; however, the particle size increased with increasing poloxamer 407 concentrations. The particle size was also observed to be increased after freeze drying. The particle size and zeta potential are depicted in Table I.

\section{Drug entrapment efficiency}

The percent entrapment was observed to vary between 41.2 to $73.8 \%$. The percentage entrapment efficiency was observed to increase with the increase in lipid (GMS) concentration from $2 \%$ to $3 \%$ (i.e., formulations batches F1 to F3). However, the concentration of lipid beyond 3\% did not show significant increase in entrapment efficiency. The percentage entrapment efficiency was observed to be decreased with the increase in concentration of poloxamer 407 from $1.5 \%$ to $4 \%$ (i.e., formulations batches P1 to P5) (Table II). It has been observed that irbesartan-loaded SLN F3 showed higher percent entrapment i.e. 73.8\% compared to other formulations.

TABLE II - Characterization of the prepared SLNs

\begin{tabular}{cc}
\hline Formulation Code & \% $\mathbf{E E} \pm \mathbf{S D}(\mathbf{n}=\mathbf{3})$ \\
\hline F1 & $54.57 \pm 3.698$ \\
F2 & $63.1 \pm 1.484$ \\
F3 & $73.8 \pm 2.121$ \\
F4 & $59.1 \pm 2.969$ \\
F5 & $46.05 \pm 3.500$ \\
P1 & $69.47 \pm 3.160$ \\
P2 & $65.21 \pm 2.057$ \\
P3 & $59.86 \pm 2.729$ \\
P4 & $44.02 \pm 1.400$ \\
P5 & $41.2 \pm 2.687$ \\
\hline
\end{tabular}

The $\%$ entrapment efficiency is expressed as Mean \pm SD.

\section{In vitro release studies}

In vitro drug release study of the selected SLNs (F1, F2, F3, F4, and F5) was carried out. The SLNs exhibited biphasic release pattern with initial release in 2 hours in $0.1 \mathrm{~N} \mathrm{HCl}$ followed by a sustained release for 48 hours. Twenty percent of the incorporated amount of drugs was found to be released during the first 2 hours, followed by a slowed release of $97 \%$ of the drug up to 48 hours. The irbesartan-loaded SLN F3 showed a better release profile of $97.58 \%$ by 48 hours. The prolonged release at 48 hours can be attributed to slow diffusion of drug from lipid matrix. The results of in vitro drug release are depicted in Table III.

\section{Selection of the optimized formulation}

It was observed that the irbesartan-loaded SLN F3 showed optimum particle size before and after freeze drying, zeta potential, high entrapment efficiency, and better release profile among the prepared batches of SLNs. Therefore, freeze dried irbesartan-loaded SLN F3 was selected for further evaluation of surface morphology and in vivo studies.

\section{Release kinetics}

The kinetics of drug release was evaluated to prove its design and performance. The mechanism and kinetics of drug release from SLN was assessed by plotting graphs of various kinetic models. The release profile of formulation F3 was found to be fitted best with Korsmeyer-Peppas model. The release kinetic profiles of the optimized formulation (irbesartan-loaded SLN F3) such as zero-order, first-order, Higuchi and KorsmeyerPeppas are shown in Figure 1.

A high correlation was observed in the KorsmeyerPeppas and zero-order plots. The rate constants were calculated from the slope of the respected plots (table IV). The $\mathrm{K}$ value was 0.6257 indicating that the release of the drug was controlled by diffusion of an anomalous type (drug diffusion in the hydrated matrix and polymer relaxation).

\section{Shape and surface morphology}

Scanning electron microscopy (SEM) of pure drug revealed small particles with slightly spherical shape (Figure 2a). In case of irbesartan-loaded SLN F3, the particles were observed to be aligned in intimate contact 
Solid lipid nanoparticles of irbesartan: preparation, characterization, optimization and pharmacokinetic studies

TABLE III - In vitro release profile of irbesartan from the freeze dried SLNs (F1 to F5)

\begin{tabular}{lccccc}
\hline $\begin{array}{l}\text { Sampling Time } \\
\text { (hour) }\end{array}$ & \multicolumn{5}{c}{ \% Cumulative Drug Release (CDR) \pm SD (n= 3) } \\
\cline { 2 - 6 } & F1 & F2 & F3 & F4 & F5 \\
\hline 0.5 & $8.58 \pm 0.947$ & $9.87 \pm 0.909$ & $7.21 \pm 2.113$ & $5.91 \pm 1.096$ & $5.05 \pm 0.565$ \\
1 & $11.23 \pm 0.472$ & $15.1 \pm 1.904$ & $10.62 \pm 0.93$ & $8.91 \pm 1.055$ & $8.03 \pm 0.748$ \\
2 & $14.75 \pm 1.328$ & $34.56 \pm 4.148$ & $15.78 \pm 0.805$ & $11.39 \pm 0.913$ & $11.16 \pm 0.590$ \\
2.5 & $19.92 \pm 0.570$ & $43.17 \pm 2.971$ & $16.57 \pm 1.176$ & $11.77 \pm 0.918$ & $9.84 \pm 3.534$ \\
3 & $21.41 \pm 1.050$ & $48.87 \pm 1.003$ & $19.80 \pm 5.11$ & $12.63 \pm 2.911$ & $9.64 \pm 4.566$ \\
4 & $24.15 \pm 0.677$ & $53.14 \pm 1.631$ & $24.20 \pm 1.012$ & $17.84 \pm 5.827$ & $13.02 \pm 3.664$ \\
5 & $30.59 \pm 1.588$ & $60.51 \pm 0.465$ & $33.15 \pm 3.329$ & $21.79 \pm 3.444$ & $18.09 \pm 4.089$ \\
6 & $40.31 \pm 0.767$ & $64.52 \pm 1.171$ & $43.51 \pm 6.476$ & $31.72 \pm 11.99$ & $24.92 \pm 6.367$ \\
8 & $40.02 \pm 2.395$ & $67.53 \pm 2.221$ & $57.69 \pm 8.039$ & $50.45 \pm 12.74$ & $42.63 \pm 11.192$ \\
12 & $41.05 \pm 3.520$ & $71.20 \pm 1.864$ & $72.92 \pm 6.248$ & $64.42 \pm 11.03$ & $54.41 \pm 5.111$ \\
24 & $58.46 \pm 1.437$ & $74.27 \pm 4.971$ & $81.96 \pm 2.891$ & $80.12 \pm 7.668$ & $75.44 \pm 4.168$ \\
48 & $61.92 \pm 0.776$ & $83.93 \pm 3.576$ & $97.58 \pm 1.854$ & $90.8 \pm 3.609$ & $88.11 \pm 3.231$ \\
\hline
\end{tabular}

The $\%$ CDR is expressed as Mean \pm SD.

TABLE IV - Release kinetics of irbesartan-loaded SLN F3

\begin{tabular}{cccccccc}
\hline \multicolumn{2}{c}{ Zero order } & \multicolumn{2}{c}{ First order } & \multicolumn{2}{c}{ Higuchi model } & \multicolumn{2}{c}{ Korsmeyer-Peppas model } \\
\hline $\mathbf{R}^{2}$ & $\mathbf{K}$ & $\mathbf{R}^{2}$ & $\mathbf{K}$ & $\mathbf{R}^{\mathbf{2}}$ & $\mathbf{K}$ & $\mathbf{R}^{\mathbf{2}}$ & $\mathbf{K}$ \\
\hline 0.9823 & 5.366 & 0.9597 & 0.1357 & 0.9496 & 15.64 & 0.9828 & 0.6257 \\
\hline
\end{tabular}
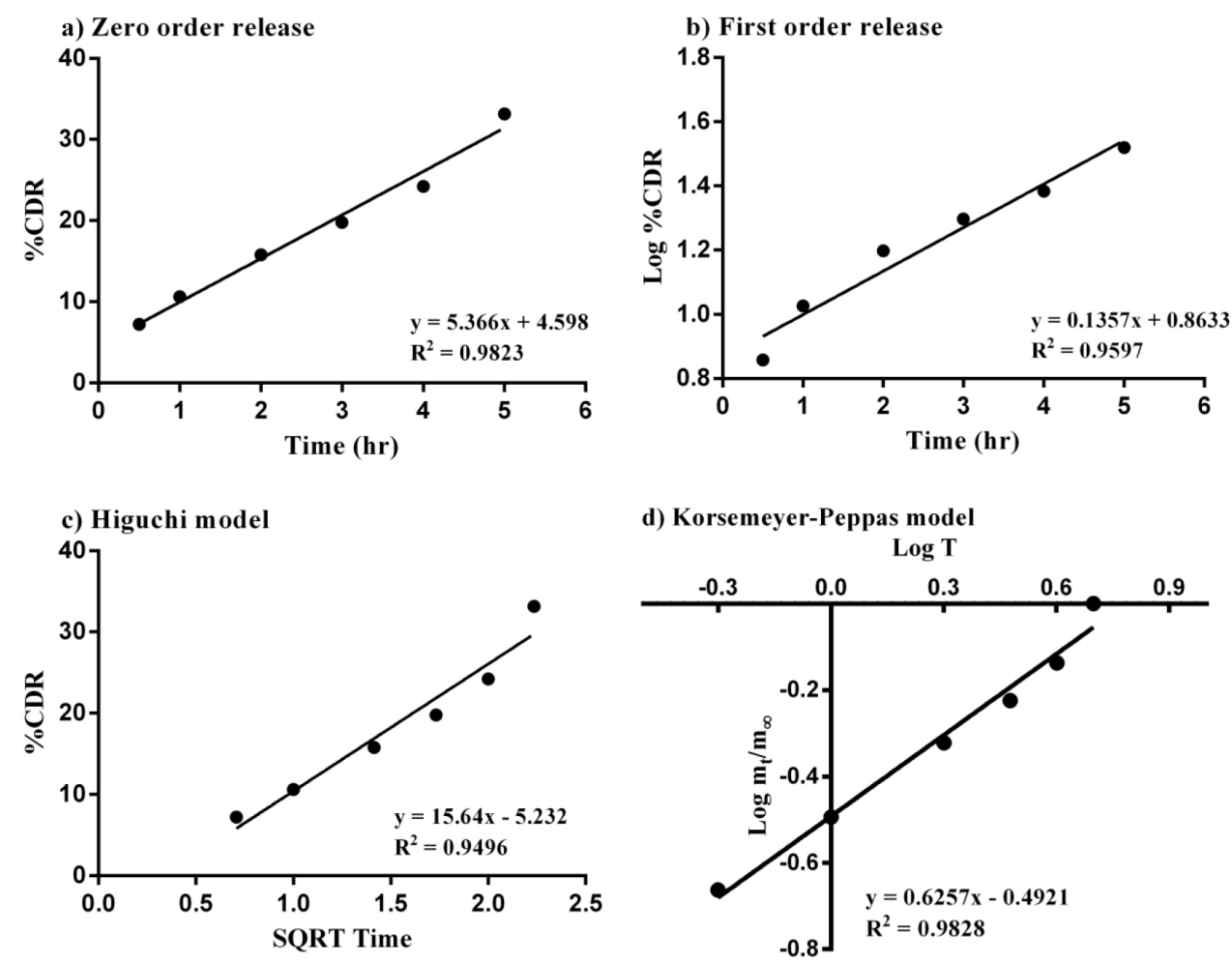

FIGURE 1 - Release profile of irbesartan-loaded SLN F3, (a) zero order, (b) first order, (c) Higuchi model and (d) KorsmeyerPeppas model. 
as fiber like structures. All the particles were observed as discrete entities, indicated that lyophilisation did not cause aggregation of particles (Figure 2b). These particles were readily redispersible. SEM analysis also revealed that interaction between solid lipid and drug lead to matrix structure, which is different from SEM image of pure drug. This indicates that drug molecules are completely dispersed in the lipid structures leading to formation of nanoparticles.

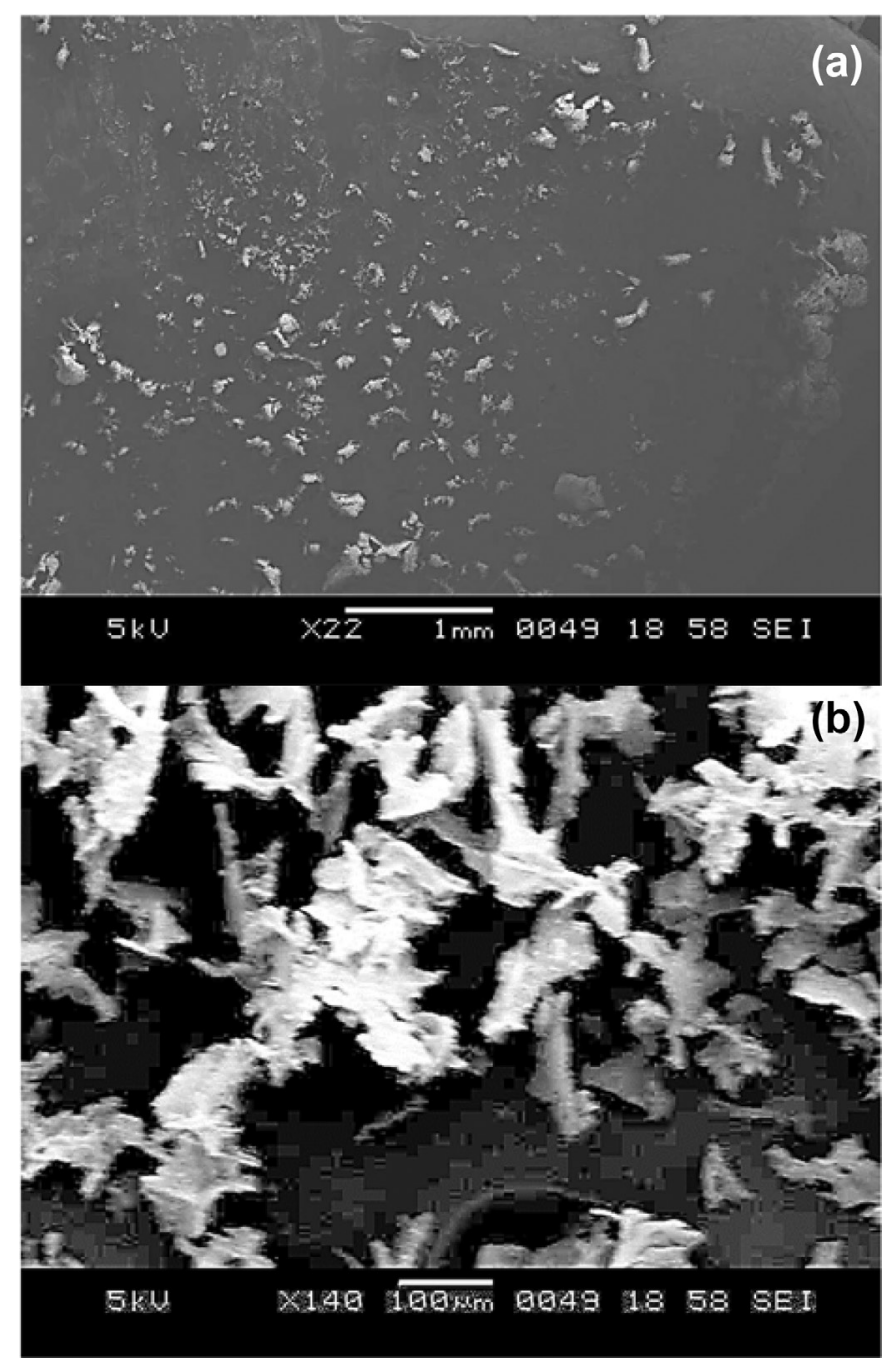

FIGURE 2 - SEM of (a) Irbesartan and (b) Irbesartan-loaded SLN F3.

\section{Differential scanning calorimetry and FT-IR spectroscopy}

The possible interaction between irbesartan and the carrier was studied by FT-IR spectroscopy and DSC. IR spectral analysis for drug alone and irbesartan-loaded SLN F3 was carried out. The principal IR peaks of pure irbesartan and irbesartan-loaded SLN F3 are shown in figures $3 \mathrm{a}$ and $3 \mathrm{~b}$. In case of irbesartan-loaded SLN F3, two peaks were missing and other peaks were found with reduced intensity compared to pure drug, indicating reduced crystallinity of drug in the formulation.

The DSC thermograms of pure irbesartan and irbesartan-loaded SLN F3 are shown in figures 4a and 4b. Pure irbesartan showed a sharp peak (endotherm) at $181^{\circ} \mathrm{C}$ corresponding to its melting point/transition temperature. There was a shift in the melting point of the drug when it was formulated into SLN indicating reduced crystallinity of drug (Singh et al., 2014).

\section{Pharmacokinetic studies}

Irbesartan-loaded SLN F3 showed significant enhancement in the systemic exposure than the pure drug (Table V). The $\mathrm{C}_{\max }$ of the SLN F3 increased by two folds and the $\mathrm{T}_{\max }$ decreased by 5.33 folds as compared to the pure drug. The SLN F3 had increased the half-life by 2 fold than the pure drug. Though the $\mathrm{T}_{\max }$ of SLN F3 was achieved within 0.75 hours, the elimination rate constant was observed to be significantly decreased, i.e., 15 times less than that of pure drug. The clearance of the SLN F3 was slightly lower, whereas higher apparent volume of distribution was observed than the pure drug. The mean residence time (MRT) of SLN F3 was observed to be increased by 1.48 fold than the pure drug. The relative bioavailability of the optimized irebesartan-loaded SLN F3 was found to be $148.03 \%$. The plasma concentration of irbesartan and irebesartan-loaded SLN F3 is depicted in Figure 5.

\section{Stability}

The stability studies were carried out at $2-8{ }^{\circ} \mathrm{C}$ and $25^{\circ} \mathrm{C} / 60 \% \mathrm{RH}$ for a period of 1 month. The mean particle size and drug content of the samples were determined as a function of storage time. The effect of storage conditions on particle size and entrapment efficiency are depicted in table VI. The stability testing after 30 days led to the conclusion that not much significant difference was observed in the particle size and entrapment efficiency of the solid lipid nanoparticles stored for 30 days.

\section{DISCUSSION}

Solid lipid nanoparticles of irbesartan were produced successfully with the solvent emulsification method using glyceryl monostearate in the present study. The objective of the formulation design was to enhance the solubility, thereby increasing the bioavailability 

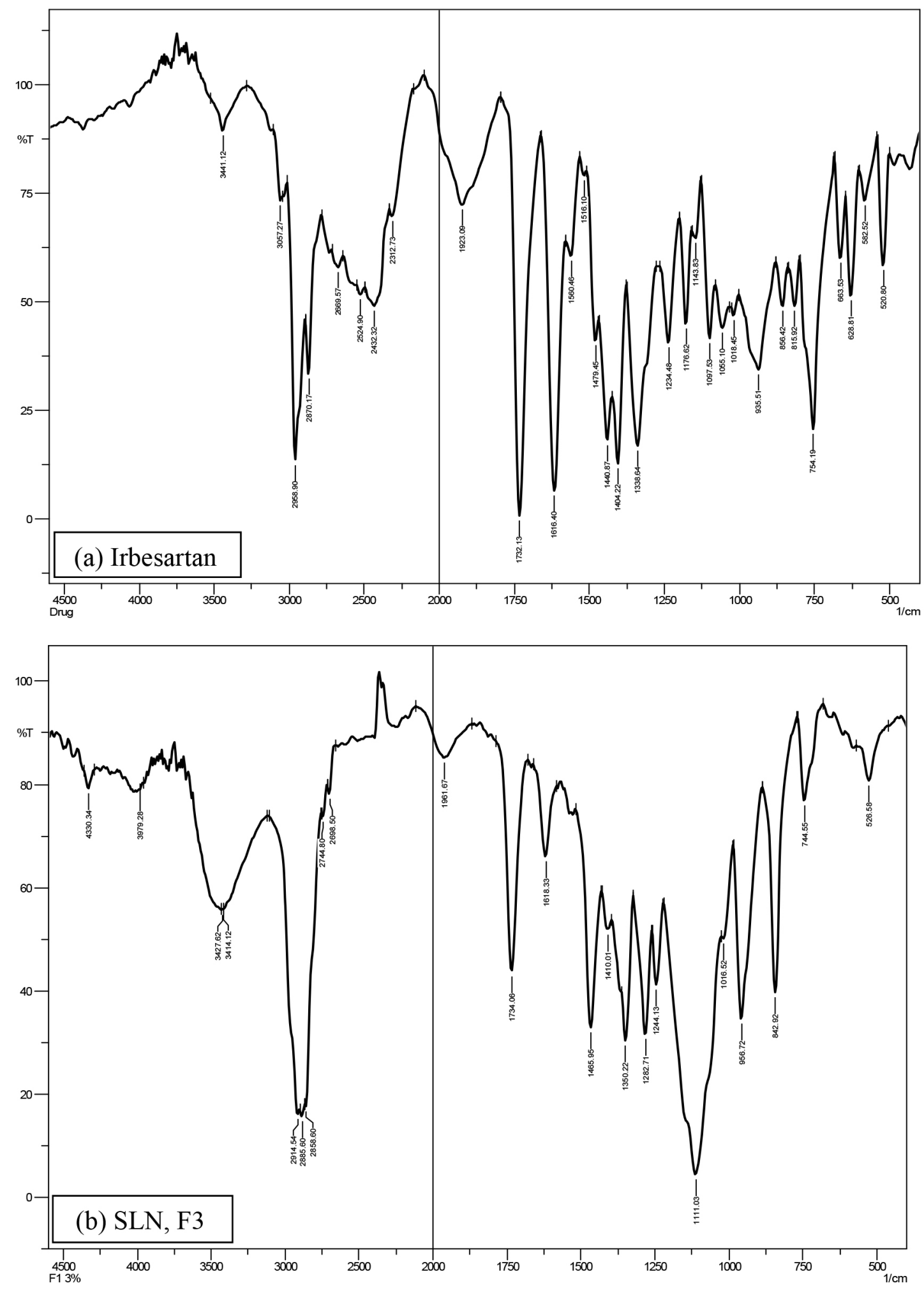

FIGURE 3 - FT-IR spectra of (a) pure drug, Irbesartan and (b) Irbesartan-loaded SLN F3.

of irbesartan. Poloxamer 407 was used to improve the stability of the prepared SLNs. Glyceryl monostearate was reported to increase solubility of drugs, therefore it was chosen for the preparation of solid lipid nanoparticles of irbesartan (Luo et al., 2006; Trotta, Debernardi, Caputo, 2003). The prepared SLN nanodispersion was freezedried after preparation to increase the shelf life of the SLNs. (Schwarz, Mehnert, 1997). The prepared SLN 


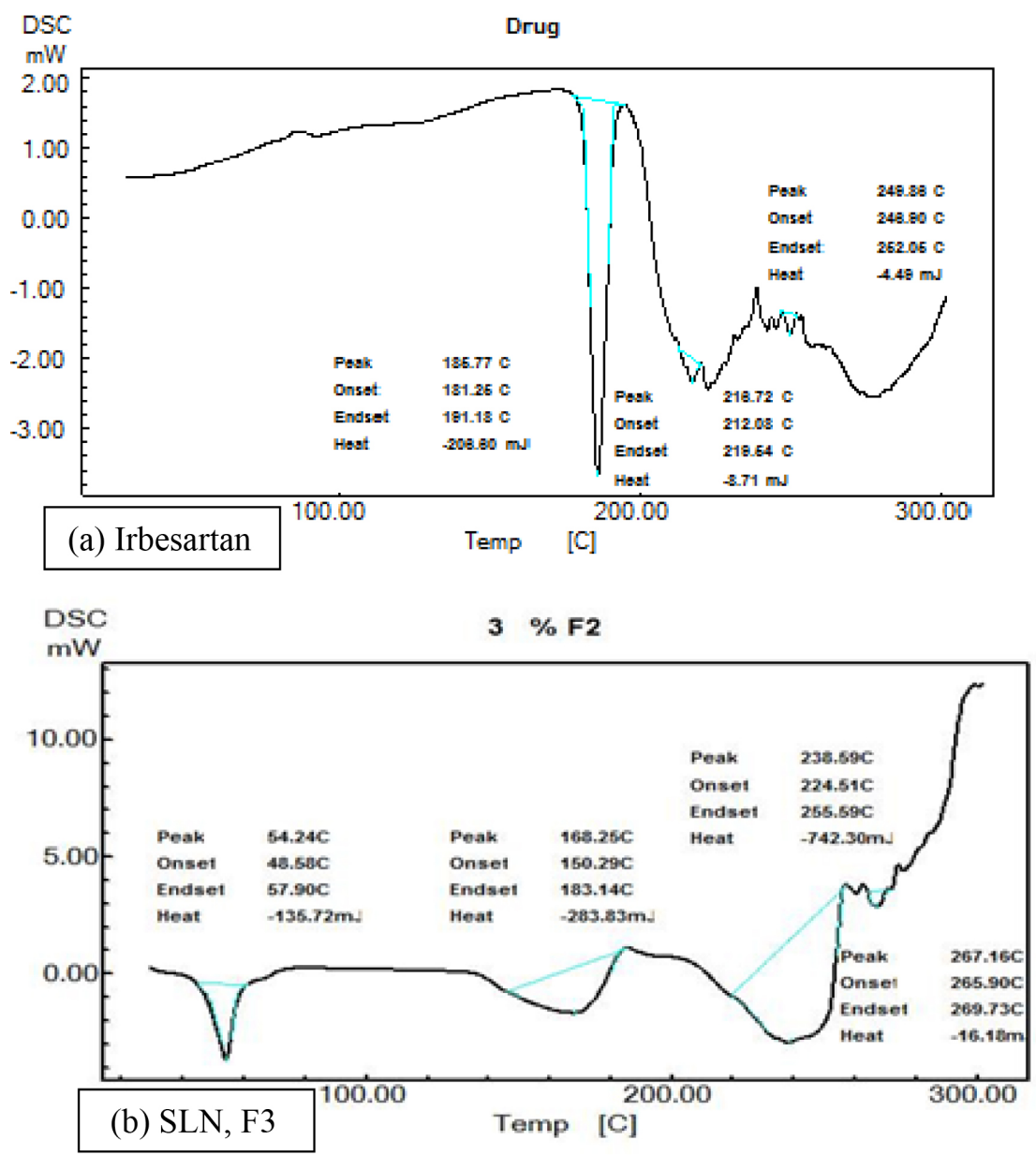

FIGURE 4 - DSC thermograms of (a) pure drug, Irbesartan and (b) Irbesartan-loaded SLN F3.

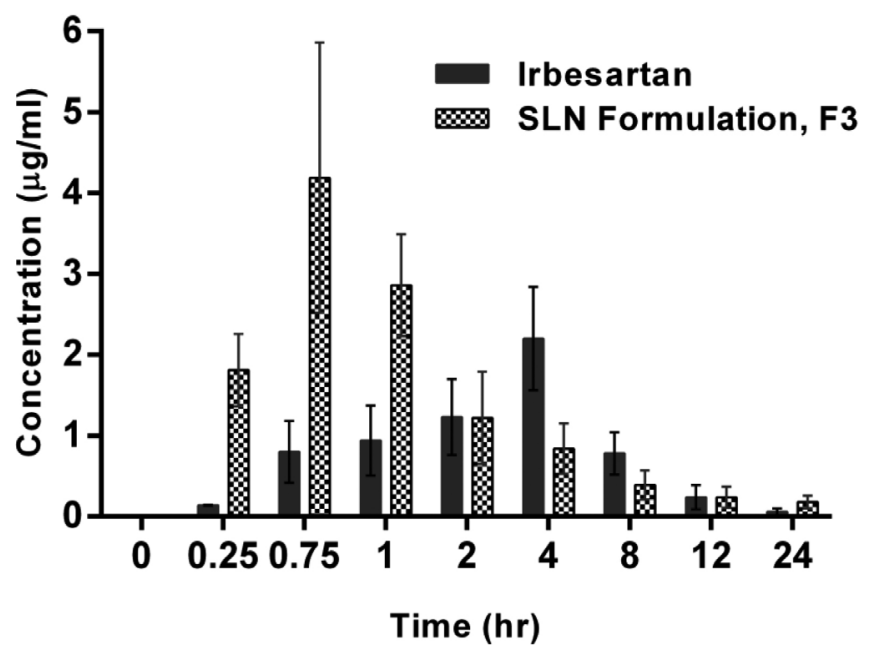

FIGURE 5 - Plasma concentration profile of irbesartan and irbesartan-loaded SLN F3.

formulations were evaluated for various physicochemical, in vitro dissolution and in vivo analysis. It was observed that the size of the prepared SLN varied by modulating lipid content. The prepared SLNs showed the mean particle size in the nanometer range and better stability. SEM analysis revealed an interaction between solid lipid and drug leading to matrix structure. This indicated that the drug molecules are completely dispersed in the lipid structures leading to formation of nanoparticles.

GMS was observed to retard the release of irbesartan of the drug in $\mathrm{pH} 7.4$ than in $0.1 \mathrm{~N} \mathrm{HCl}$ in in vitro release studies as reported earlier that the lipid matrix could retard the release of the drug (Witzleb et al., 2012). The release of irbesartan from the optimized formulation F3 showed best fit to Korsmeyer-Peppas equation. This showed the non-fickian mode of irbesartan release from the optimized formulation F3. These observations indicated that the drug release was not because of water penetration into the matrix, which explained the characteristic of a lipid-based system and zero order kinetics could be attributed to the release of drug by diffusion (Rosiaux et al., 2014; Silva et al., 2012).

The pharmacokinetic studies in rats showed significant increase of the relative bioavailability of the optimized SLN formulation F3 as compared to pure 
Solid lipid nanoparticles of irbesartan: preparation, characterization, optimization and pharmacokinetic studies

TABLE V - Pharmacokinetic parameters of irbesartan and irbesartan-loaded SLN F3

\begin{tabular}{cccc}
\hline Parameters & Units & Irbesartan & $\begin{array}{c}\text { Irbesartan-loaded } \\
\text { SLN F3 }\end{array}$ \\
\hline $\mathrm{T}_{\max }$ & $\mathrm{hr}$ & $4.00 \pm 0.5$ & $0.75 \pm 0.28^{*}$ \\
$\mathrm{C}_{\max }$ & $\mu \mathrm{g} / \mathrm{ml}$ & $2.20 \pm 0.56$ & $4.19 \pm 0.74^{*}$ \\
$\mathrm{AUC}(0-\infty)$ & $\mu \mathrm{g} . \mathrm{hr} / \mathrm{m}$ & $15.20 \pm 2.67$ & $22.50 \pm 5.45$ \\
$\mathrm{~T}_{1 / 2}$ & $\mathrm{hr}$ & $4.62 \pm 0.85$ & $9.09 \pm 1.52^{*}$ \\
$\mathrm{CL}$ & $\mathrm{L} / \mathrm{hr}$ & $0.66 \pm 0.12$ & $0.44 \pm 0.08$ \\
$\mathrm{~V}_{\mathrm{d}}($ Apparent $)$ & $\mathrm{L}$ & $4.39 \pm 0.95$ & $5.83 \pm 1.28$ \\
$\mathrm{~K}_{\mathrm{el}}$ & $1 / \mathrm{hr}$ & $0.15 \pm 0.02$ & $0.01 \pm 0.005^{*}$ \\
$\mathrm{MRT}$ & $\mathrm{hr}$ & $6.00 \pm 1$ & $8.90 \pm 1.56$ \\
Relative F & $\%$ & - & $148.03 \pm 15.42^{*}$ \\
\hline
\end{tabular}

The values are expressed as Mean \pm SD. $*$ shows significant difference in parameters at $p<0.05$ as compared to irbesartan.

TABLE VI - Effect of storage on particle size and entrapment efficiency of irbesartan-loaded SLN F3

\begin{tabular}{|c|c|c|c|c|c|c|}
\hline \multirow{2}{*}{$\begin{array}{l}\text { Storage } \\
\text { Conditions }\end{array}$} & \multicolumn{3}{|c|}{$\begin{array}{l}\text { Particle size }(\mathrm{nm}) \\
(\text { Mean } \pm \text { SD) }\end{array}$} & \multicolumn{3}{|c|}{$\begin{array}{c}\text { Entrapment efficiency (\%) } \\
(\text { Mean } \pm \text { SD) }\end{array}$} \\
\hline & Initial & 15 days & 30 days & Initial & 15 days & 30 days \\
\hline $2-8^{\circ} \mathrm{C}$ & $629.2 \pm 14.7$ & $634 \pm 10.22$ & $640.5 \pm 8.12$ & $73.8 \pm 2.12$ & $72.6 \pm 1.98$ & $71.19 \pm 1.77$ \\
\hline $25^{\circ} \mathrm{C} / 60 \% \mathrm{RH}$ & $629.2 \pm 14.7$ & $632 \pm 9.41$ & $638.8 \pm 5.81$ & $73.8 \pm 2.12$ & $71.9 \pm 1.75$ & $71.09 \pm 1.46$ \\
\hline
\end{tabular}

The values are expressed as Mean \pm SD.

drug. The $\mathrm{T}_{\max }$ of the formulation F3 was observed to be decreased, which could be attributed to the adsorbed drug on the surface of the SLN. The clearance of the formulation was observed to be decreased resulting in sustained action. The possible reason for the reduced clearance could be slow release of irbesartan form the core of lipid moiety. The stability studies did not show any significant difference in size, entrapment efficiency and physical appearance of the irbesartan-loaded SLN F3 indicating its good stability.

\section{CONCLUSION}

It can be concluded that the prepared solid lipid nanoparticles of irbesartan using GMS and poloxamer 407 has enhanced bioavailability with sustained release of the drug. Further, it can be said that SLN could be an alternative approach to other colloidal drug delivery systems and tablets for enhancing the bioavailability of the drugs and achieving sustained release action.

\section{CONFLICT OF INTEREST}

The authors declare that there is no conflict of interest. The authors alone are responsible for content and writing of the paper.

\section{ACKNOWLEDGEMENT}

The authors are thankful to Manipal University for providing the facilities and instruments to carry out this work.

\section{REFERENCES}

ARUMUGAM, K.; CHAMALLAMUDI, M.R.; MALLAYASAMI, S.R.; GANESAN, S.; SHAVI, G.V.; AVERINENI, R.; REDDY, R.; BHAT, K.M.; UDUPA, N. Gender differences in the pharmacokinetics of rivastigmine in rats. Arzneimittel-Forsch., v.59, n.10, p.493-497, 2009.

DAVI, H.; TRONQUET, C.; MISCORIA, G.; PERRIER, L.; DUPONT, P.; CAIX, J.; SIMIAND, J.; BERGER, Y. Disposition of irbesartan, an Angiotensin II AT1-receptor antagonist, in mice, rats, rabbits and macaques. Drug Metab. Dispos., v.28, n.1, p.79-88, 2000. 
ERK, N. Simultaneous determination of irbesartan and hydrochlorothiazide in human plasma by liquid chromatography. J. Chromatogr. B., v.784, n.1, p.195201, 2003.

GANAPURAM, B.R.; ALLE, M.; DADIGALA, R.; KOTU, G.M.; GUTTENA, V. Development, evaluation and characterization of surface solid dispersion for solubility and dispersion enhancement of irbesartan. J. Pharm. Res., v.7, n.6, p.472-477, 2013.

HIRLEKAR, R.; KADAM, V. Preformulation study of the inclusion complex irbesartan- $\beta$-cyclodextrin. AAPS Pharm Scitech., v.10, n.1, p.276-281, 2009.

LUO, Y.; CHEN, D.; REN, L.; ZHAO, X.; QIN, J. Solid lipid nanoparticles for enhancing vinpocetine's oral bioavailability. J. Control. Rel., v.114, p.53-59, 2006.

MEHNERT, W.; MADER, K. Solid lipid nanoparticles: Production, characterization and applications. Adv. Drug Deliver. Rev., v.47, n.2/3, p.165-196, 2001.

MULLER, R.H.; MADER, K.; GOHLA, S. Solid lipid nanoparticles (SLN) for controlled drug delivery - a review of the state of the art. Eur. J. Pharm. Biopharm., v.50, n.1, p.161-177, 2000.

ROSIAUX, Y.; JANNIN, V.; HUGHES, F.; MARCHAUD, D. Solid lipid excipients - Matrix agents for sustained drug delivery. J. Control. Rel., v.188, p.18-30, 2014.

SCHWARZ, C.; MEHNERT, W. Freeze-drying of drug-free and drug-loaded solid lipid nanoparticles (SLN). Int. J. Pharm., v.157, n.2, p.171-179, 1997.
SILVA, A.C.; AMARAL, M.H.; GONZALEZ-MIRA, E.; SANTOS, D.; FERREIRA, D. Solid lipid nanoparticles (SLN) - based hydrogels as potential carriers for oral transmucosal delivery of Risperidone: preparation and characterization studies. Colloids Surf., B., v.93, p.241248, 2012.

SINGH, B.; VUDDANDA, P.R.; VIJAYAKUMAR, M.R.; KUMAR, V.; SAXENA, P.S.; SINGH, S. Cefuroxime axetil loaded solid lipid nanoparticles for enhanced activity against S. aureus biofilm. Colloids Surf., B., v.121, p.92-98, 2014.

TROTTA, M.; DEBERNARDI, F.; CAPUTO, O. Preparation of solid lipid nanoparticles by a solvent emulsificationdiffusion technique. Int. J. Pharm., v.257, n.1/2, p.153-160, 2003.

UNER, M. Preparation, characterization and physicochemical properties of solid lipid nanoparticles (SLN) and nanostructured lipid carriers (NLC): their benefits as colloidal drug carrier systems. Pharmazie., v.61, n.5, p.375-386, 2006.

WITZLEB, R.; MULLERTZ, A.; KANIKANTI, V.R.; HAMANN, H.J.; KLEINBUDDE, P. Dissolution of solid lipid extrudates in biorelevant media. Int. J. Pharm., v.422, n.1/2, p.116-124, 2012.

ZHANG, Z.; LE, Y.; WANG, J.; ZHAO, H.; CHEN, J. Irbesartan drug formulated as nanocomposite particles for the enhancement of the dissolution rate. Particuology, v.10, n.4, p.462-467, 2012.

Received for publication on $17^{\text {th }}$ January 2015 Accepted for publication on $18^{\text {th }}$ November 2016 